rather lengthy for there may be associated features in this condition such as ophthalmoplegia, dementia, extrapyramidal signs, and optic atrophy. These occur at random within families and therefore do not indicate genetic heterogeneity.

The chapters on the spastic paraplegias are as clear and sensible as the preceding ones. Anita Harding emphasises the importance of examining parents: five of her 19 families with autosomal dominant spastic paraplegia had previously been classified as autosomal recessive because of a failure to do this. There is a chapter on differential diagnosis and investigations that is particularly useful for clinicians. The final excellent chapter on genetic counselling gives empirical risks of recurrence for different situations: presence or absence of family history, age of onset, predominant signs. However, the use of cumulative frequency curves for age of onset, which have been based on ages of onset of a series of patients, gives genetic prognoses that are too optimistic.

Anita Harding has written extensively on the ataxias and paraplegias but there is much that is new in this monograph and therefore a good acquaintance with Brain and Journal of Neurology, Neurosurgery, and Psychiatry does not excuse one from buying this very good book. It is clearly written, full of common sense, and of great practical use to every clinical geneticist and neurologist.

SARAH BundeY

\section{Annual Review of Genetics}

Edited by Herschel L Roman. (Pp 628; figures + tables. \$30.00.) USA: Annual Reviews Inc. 1984.

The main value in a review series such as this is for the reader to gain information on advances outside his own immediate field. This volume certainly fills that need; almost anyone in Medical Genetics, or indeed any branch of Human Genetics, will find a number of chapters that are well worthwhile, not necessarily those closest to his particular interest.

The sixteen reviews cover a wide range of topics. The one that I found especially fascinating was the first one by Rhoades on 'The early years of maize genetics'. It does all human geneticists good to recognise how much they owe to plant genetics, and how often plant geneticists had sorted out a fundamental principle years or decades before it was even recognised in man. Nowhere is this more clearly illustrated than in the history of genetic linkage, where Rhoades vividly describes how in 1928 a group of twelve maize geneticists (himself included) sat in a hotel bedroom and agreed informally to assign, on a collaborative basis, the ten recognised linkage groups to individual chromo- $\vec{F}$ somes, each worker taking on a specific linkage $\stackrel{\vec{P}}{+}$ group. Only now, over 50 years later, is this becoming feasible for man. (Those molecular 흘 biologists who believe that linkage studies started $\frac{\text { क }}{\partial}$ with DNA polymorphisms please read this chapter!) $\stackrel{\varnothing}{\varrho}$

Other useful chapters are a comprehensive review के of trisomy in man by Hassold and Jacobs; despite a $\vec{\bullet}$ wealth of facts we remain extraordinarily ignorant of the causes. Cytogeneticists will also appreciate the $\vec{\omega}$ chapter by Von Wettstein on the synaptonemal $\stackrel{\mathscr{S}}{\Omega}$ complex. Orkin and Kazazian review the human $\beta \overline{3}$ globin gene from all aspects, while Varmus gives an is interesting account of cellular oncogenes. The chap- ? ter by Syvanen of evolutionary implications of $\vec{\omega}$ mobile genetic elements covers a topic that is likely to become increasingly relevant to human disorders. فे

Other readers will enjoy different chapters not 응 mentioned here; certainly anyone wishing to extend his horizons will enjoy this valuable and well $\longrightarrow$ produced volume.

\section{Peter S HARPER}

Mutagenicity, Carcinogenicity, and Teratogenicity of Industrial Pollutants

Edited by M Kirsch-Volders. (Pp xiv +336 ; figures + tables. \$45.00.) New York, London: Plenum Press. 1984

This text outlines a number of aspects of the $\frac{\text { 의 }}{3}$ toxicology of selected groups of environmental $\bar{F}$ chemicals which include industrial metals, solvents, $\overrightarrow{0}$ insecticides, and monomers such as styrene and vinyl chloride. The collection of individual papers provides a useful source of information for the $\dot{0}$ reader wishing to initiate a study of any of the compounds discussed. However, the reader should $\delta$ be aware that the contents of the book do not $₹$ correspond to the generality of the title and it is only $\mathrm{O}$ mutagenicity data that can be considered to be $>$ discussed in any real depth for the majority of chemicals.

The book contains a number of interesting chap- $\stackrel{N}{\sigma}$ ters and I refer the reader particularly to chapter $1, N$ which provides a comprehensive discussion of the mechanisms of mutagenesis and carcinogenesis 0 which may be useful to the reader unfamiliar with the field, together with some original points to stimulate the specialist. It is to be regretted that the $\stackrel{0}{+}$ book does not contain a similar series of chapters on 0 teratogenicity and embryotoxicology which would ${ }_{0}$ have provided a valuable background to the indi- $\stackrel{\mathbb{\nabla}}{\Omega}$ vidual chemical chapters.

This would have been a much more useful book if 
it had shown the hand of a strong editor. As the book stands, the chapters are variable in style and usefulness and its main strength lies in the tables and comprehensive references. This variation in style is illustrated by the differences between the chapters in the presentation of data from bacterial mutagenicity tests; in some chapters positive results are simply reported, whereas in others the authors attempt to interpret results for the reader.
The great problem with any book of this type is that its contents can rapidly become outdated as new data accumulate. To have more than a passing value to this reader I would have appreciated considerably more interpretation of the data than has been attempted in most of the chapters collected together in this book.

J PARry 